\title{
Impact of Different Weather Years on the Design of Hydrogen Supply Pathways for Transport Needs
}

\section{Dilara Gulcin Caglayan, ${ }^{1,2}$ Heidi U. Heinrichs, ${ }^{1}$ Jochen Linssen, ${ }^{1}$ Martin Robinius ${ }^{1}$ and Detlef Stolten $^{1,2}$}

1 Institute of Energy and Climate Research - Electrochemical Process Engineering (IEK-3) Forschungszentrum Juelich GmbH, 52425 Juelich, Germany

2 RWTH Aachen University, c/o Institute of Energy and Climate Research - Electrochemical Process Engineering (IEK-3)Forschungszentrum Juelich GmbH, 52425 Juelich, Germany

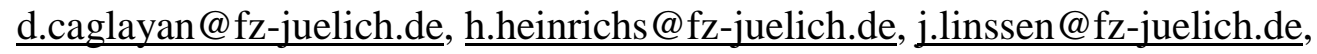
m.robinius@fz-juelich.de, $\underline{\text { d.stolten@fz-juelich.de }}$

\begin{abstract}
Renewable energy sources (RES) will play a crucial role in future sustainable energy systems. In scenarios analyzing future energy system designs, a detailed spatial and temporal representation of renewable-based electricity generation is essential. For this, sufficiently representative weather data are required. Most analyses performed in this context use the historical data of either one specific reference year or an aggregation of multiple years. In contrast, this study analyzes the impact of different weather years based on historical weather data from 1980 through 2015 in accordance with the design of an exemplary future energy system. This exemplary energy system consists of on- and offshore wind energy for power-to-hydrogen via electrolysis, including hydrogen pipeline transport for most southwestern European countries. The assumed hydrogen demand for transportation needs represents a hypothetical future market penetration for fuel cellelectric vehicles of $75 \%$. An optimization framework is used in order to evaluate the resulting system design with the objective function of minimizing the total annual cost (TAC) of the system. For each historical weather year, the applied optimization model determines the required capacities and operation of wind power plants, electrolyzers, storage technologies and hydrogen pipelines to meet the assumed future hydrogen demand in a highly spatially- and temporally-detailed manner, as well as the TAC of the system. Following that, the results of every individual year are compared in terms of installed capacities, overall electricity generation and connection to the transmission network, as well as the cost of these components within each region. The results reveal how sensitive the final design of the exemplary system is to the choice of the weather year. For example, the TAC of the system changes by up to $20 \%$ across two consecutive weather years. Furthermore, significant variation in the optimization results regarding installed capacities per region with respect to the choice of weather years can be observed.
\end{abstract}

Keywords: Variable renewable energy, wind energy, weather years, optimization, power-tohydrogen. 


\section{INTRODUCTION}

Carbon dioxide constituted nearly three fourths of global greenhouse gas emissions (GHGs) in 2017; moreover, almost $90 \%$ of this gas derived from the combustion of fossil fuels [1]. Increases in GHG emissions and decreases in the quantity of fossil fuels have triggered a shift towards renewable energy systems in recent years. For instance, the global installed capacity of renewable energy technologies has increased by $1256 \mathrm{GW}$ between the years 2000 and 2016, $745 \mathrm{GW}$ of which constitutes wind and solar energy [2]. Although variable renewable energy sources (VRES) are environmental friendly, available across the world and rapidly decreasing in cost, their intermittency remains the main obstacle to a VRES-based energy system [3]. To address this issue, excess power from VRES, which occurs when power generation is higher than demand, can be transformed into a chemical energy carrier. This energy carrier can later be used for either grid balancing or direct use in other processes in the energy system. Considering its high energy density, low storage cost and the fact that it is carbon-free, hydrogen is a promising chemical energy carrier. It can be produced by splitting water via electrolyzers, stored in vessels or caverns and, finally, can be utilized in fuel cells to produce electricity in the power sector, in fuel cellelectric vehicles in the transport sector or in heavy industry as a feedstock. Moreover, it enables a wide range of sector coupling options [4]. The use of hydrogen as a chemical energy carrier at peak power periods is called "Power to Hydrogen (P2H)". Schiebahn et al. [5] discuss multiple uses of hydrogen from $\mathrm{P} 2 \mathrm{H}$ for three scenarios in Germany. They conclude that the utilization of hydrogen in the transportation sector could have a business case, owing to the comparatively high efficiency of fuel cell vehicles.

In the literature, various studies can be found on energy system design considering VRES with different spatial and temporal resolutions, as well as various reference weather years, which are used in the estimation of generation via VRES. Samsatli et al. used weather data from 2014 for the optimal design and operation of a wind-hydrogen-electricity network in Great Britain to meet hydrogen demand for the transportation sector by employing a spatio-temporal optimization model [6]. Duigou et al. investigated the techno-economic feasibility for large scale hydrogen underground storage in France, considering hydrogen for transportation sector in the year 2050 [7]. For this analysis, wind production time series data were obtained by drawing on the wind profile of 2005. Meanwhile, Robinius et al. [8] analyzed the linking of the German power and transport sectors by means of a highly detailed spatial and temporal model in which the parameters for a Weibull distribution were obtained by using measured wind speeds between 1981 and 2000. For time series, amongst the available measured data collected from weather stations between 2010 and 2013, 2012 was chosen, as 205 of 403 weather stations had a complete dataset [8]. Welder et al. [9] looked into a wind-based energy system to supply hydrogen demand for the transportation sector and industry by employing a spatio-temporal optimization model for Germany on the basis of the weather year 2012 in order to compare the results with those presented by Robinius et al. [8]. In the model documentation of EnergyPLAN [10], consideration of different weather years is mentioned for 1996, 2000 and 2001. In their analysis across Europe, Heide et al. [11,12] considered the years between 2000 and 2007 by taking a monthly average over 96 months for total European 
wind power generation. The approach, suggested by Heidi et al. [11,12], has been employed for the modeling of wind energy by other studies [13,14]. Bogdanov et al. [15] used data for 2005 with $0.45^{\circ} \times 0.45^{\circ}$ spatial resolution for their investigations of the electricity, gas and heat supply options across northeastern Asia. The same dataset and year is included in the study of Gulagi et al. [16] for India and the region of the South Asian Association for Regional Cooperation (SAARC), claiming that installed capacities of renewables would not be drastically affected by the choice of weather year. For the analysis of 100\% renewable electricity scenarios in Australia, 2010 was chosen by Elliston et al. [17]. Budischak et al. [18], in turn, examine an electricity system with 90-99.9\% renewable energy in the Eastern United States by drawing on weather years between 1999 and 2002. Fripp [19] employs 2004 for an investigation in California with high shares of renewables. From these studies, it is apparent that weather years are mostly chosen in accordance with data availability. Moreover, it can be seen that in some studies, the applied weather year or source of the data are not even specified [20-26]. Pfenninger [27] conducted an analysis of the reduction of time resolution and inter-annual variability of wind and PV time series in energy models by using 25 years of data (1990-2014) for Great Britain. Nevertheless, application on a smaller regional scope such as Great Britain might not adequately cover different weather phenomena.

Although variation in wind power generation is recognized in the context of wind energy and its potential by an EEA report [28] and Banuelos-Ruedas et al. [29], the impact of this variation in energy system design has not been discussed in detail. Until now, most studies in this realm have focused on one year for wind power generation in the context of energy system design without explaining the reason for choosing that specific year. However, to the authors' knowledge, a systematical approach to the selection of different weather years for energy system design has not yet been investigated. In addition, the robustness of the design has not been examined in the case of a different weather year selection. This study presents an analysis based on 37 weather years ranging from 1980 to 2016 in order to investigate the impact on the final design of an exemplary energy system that utilizes wind energy to produce hydrogen for the transportation sector. In order to observe the influence of wind power generation time series data, a spatio-temporal optimization model is employed for a case study that includes Germany, the Netherlands, Belgium, Luxemburg, Switzerland, France and Italy.

The uniqueness of this study comes from the application and consideration of many historical weather years on the basis of a VRE-based energy system design. The investigation of differences in the individual system designs from the selection of a weather year can pinpoint the robustness of the existing approach applied by several literature sources. Moreover, the variation can be better observed through the use of an optimization model as a tool, especially when the installed capacities of the related technologies are determined with a minimization of cost. The deviations in the installed capacities can be used as an indication of the robustness of the system design. Furthermore, taking into account the different weather phenomena within a larger regional scope, these seven Central European countries are chosen as the region of interest. The results of the presented analysis show different energy system designs and their comparisons when only the 
weather year (hence the wind energy generation time series) is altered. Moreover, means of attaining a robust system design are sought. In the following, a methodology involving the assumptions and scenario definition is described in Section 2. Investigation of average full load hours for onshore and offshore wind energy, energy system designs and their interpretation, installed capacities and costs of system components are showed and discussed in Section 4. Finally, conclusions derived from the findings are presented in Section 5.

\section{METHODOLOGY}

In this section, the modeling approach and the preparation of the input parameters of the model are explained. The definition of the optimization model and the exemplary scenario are explained in Section 2.1. While using the same model and scenario definition, 37 model runs for each weather year (between 1980 and 2016) are performed independently by altering the wind generation time series of the corresponding year. Following this, the input parameters required for the model and how these parameters are estimated are presented in Section 2.2.

\subsection{Model approach}

The open source energy modeling framework used to build the model is called, "Framework for Integrated Energy Systems Assessment (FINE)" [30]. In order to achieve reasonable model run times, time series aggregation [31,32] is applied to aggregate the hourly resolution of one year for all demand and VRES generation time series data to 30 representative days, each with 24 hourly values. Further details about the underlying optimization methodology are thoroughly discussed by Welder et al. [9], including the mathematical representation of the framework and the constraints.

Figure 1 shows the model input and output, as well as the representation of the exemplary system chosen for this analysis. As can be seen from the figure, the input parameters required by the model can be classified into five groups: demand, generation, conversion, transmission and storage. In this scenario, hourly time series data is defined for generation and demand. Afterwards, time series aggregation [31,32] is applied to this hourly data and 8760 time steps is decreased to 720 time steps (30 typical days, 24 hours per day). Constraints defined in the optimization framework include supplying energy demand and any time and region without violating technical limits such as the injectability of salt caverns or the maximum allowable capacity of onshore wind turbines in a region.

Central European countries, including Germany, the Netherlands, Belgium, Luxemburg, Switzerland, France and Italy were chosen as region of interest. Overall, the geometry of these regions covers different offshore wind turbine structures (Germany, the Netherlands, Belgium, France and Italy), such as different foundations caused by variations in the water depth and average wind speeds, as well as weather phenomena in both the Mediterranean and Baltic Sea regions, as well as the mountainous terrain, therefore leading to a high degree of weather variability. In terms of demand, only hydrogen demand for passenger vehicles is investigated. Onshore and offshore wind turbines are considered as two separate generation technologies. Hydrogen is produced by 
means of Polymer Electrolyte Membrane (PEM) electrolyzer, which is defined as a conversion technology. However, additional conversion technologies, especially for re-electrification, are not taken into account, as only hydrogen demand is considered. As pipelines are considered the best option for large quantities and long distances [33], hydrogen transmission between regions is only possible via them. Finally, salt caverns are considered a storage technology for seasonal hydrogen storage owing to their low cost. However, the storage of gaseous hydrogen in vessels is also enabled, since salt caverns are not available in all regions. Detailed explanations of the preparation of the techno-economic parameters for these technologies as inputs to the model are available in Section 2.2. Once the system has been optimized, the output of the optimal energy system design can be obtained. These results consist of the optimal installed capacities and the total annual cost of the technologies, as well as the hourly operation time series for each region. Moreover, the optimal infrastructure design of each transmission technology (in this analysis only hydrogen pipeline) can be obtained.

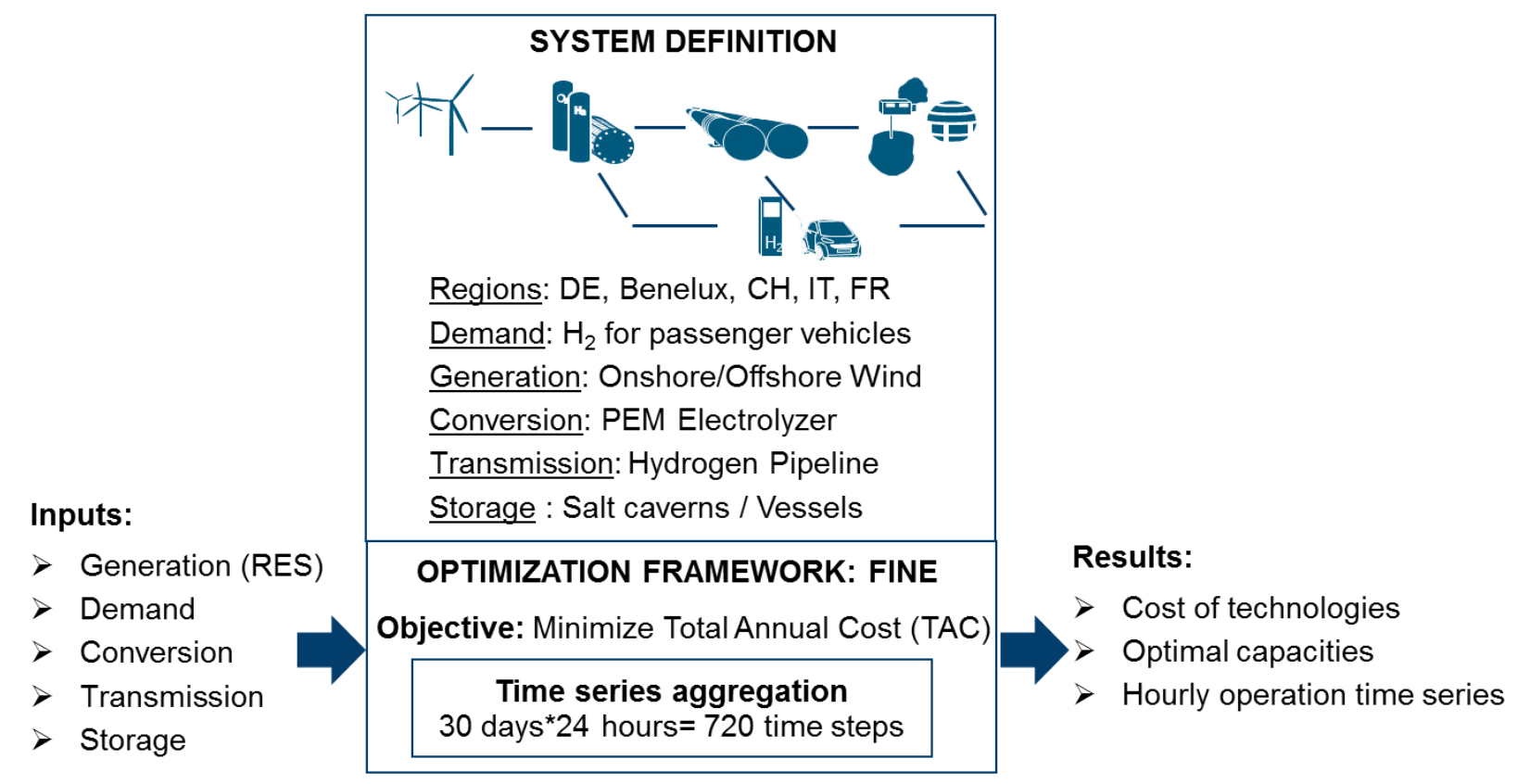

Figure 1. Representation of exemplary system and methodology used in the analysis.

The model represented in Figure 1 is employed to observe the influence of different weather years. Only the generation time series for onshore and offshore wind energy are changed in each model run with respect to the investigated year. Nevertheless, the maximum available capacities and the availability of each technology, as well as the economic parameters are kept constant in all model runs. For comparison, optimal installed capacities of mainly onshore and offshore wind turbines, but also electrolyzer, pipelines and storage technologies are investigated.

\subsection{Input parameters}

The determination of input parameters such as wind generation time series data, the regional availability of storage technologies, hydrogen demand for passenger vehicles and the connection 
of the regions for hydrogen transmission are explained in the following sections. Investment cost, operational expenditure (OPEX) and the economic lifetime of all technologies used in the analysis can be found in the supplementary material. In addition to the investment cost of wind turbines, there is no variation in the cost parameters with respect to the regions.

\subsubsection{Hydrogen demand}

Electricity generated by wind turbines is converted into hydrogen to supply demand at any time. The yearly hydrogen demand of a country is calculated following the method applied by Robinius et al. [4], of multiplying population, car ownership, average annual driving distance of passenger vehicles, fuel consumption of fuel cell-electric vehicles (FCEVs) of $0.0071 \mathrm{~kg} \mathrm{H} / \mathrm{km}$ and the market penetration of FCEVs, which in this analysis is assumed to be $75 \%$. Countryspecific parameters such as population, car ownership and annual driving distance are listed in the supplementary material. National hydrogen demands are further spatially distributed to each of the 16 subnational regions of this study by $1 \mathrm{~km}$ population density data [34]. The demand centers, which are used in the calculation of transmission distances between regions, are estimated by weighted centroids, as the spatial resolution of hydrogen demand is also performed by using the population distribution. Yearly hydrogen demand for each region is projected onto an hourly demand profile of a reference fueling station.

\subsubsection{Hydrogen transmission}

Hydrogen pipelines are considered a hydrogen transmission technology between regions, as they are generally found to be the most the cost-optimal solution to transporting hydrogen for large distances and demand (more than $200 \mathrm{~km}$ distance between regions and nearly 60 tons $\mathrm{H}_{2}$ /day) [33]. Figure 2 shows the possible pipeline connections defined in the model, as well as the salt cavern availability in the regions. Pipeline connections between regions are only allowed between adjacent regions. For example, direct hydrogen transmission from Switzerland to western France is not possible; nevertheless, it can be transmitted across southern France. In order to determine pipeline routing, the shortest paths between region centroids are determined from the combination of existing natural gas pipelines [35] and railways [36]. Corsica, for instance, has no railway or natural gas pipeline connection to the other regions, whereas a pipeline connection between Italy and Sardinia exists. Nevertheless, Corsica and Sardinia are disconnected from other regions in order to observe the effect of weather year selection independent of hydrogen transportation. 


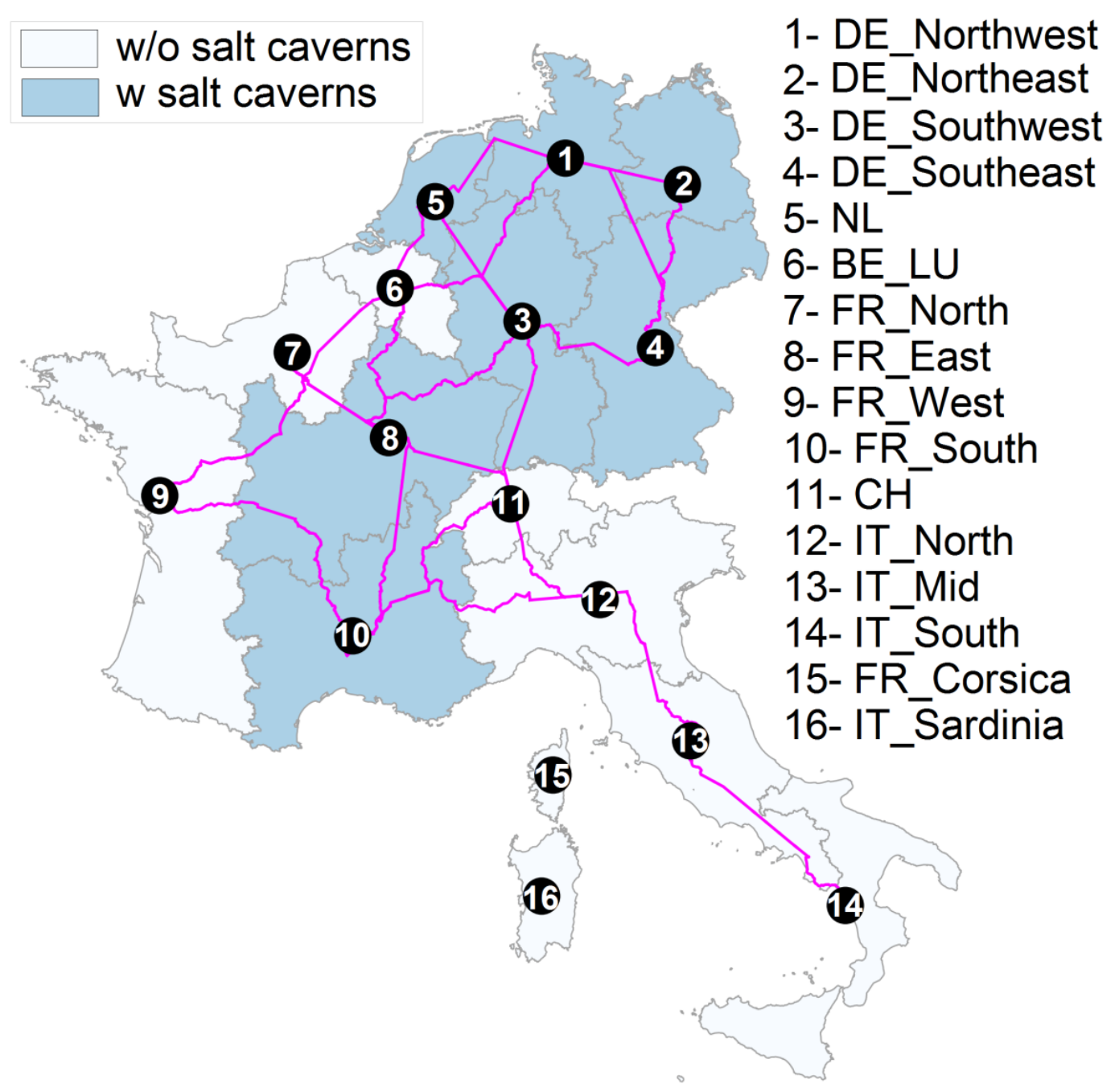

Figure 2. Region of interest with possible pipeline connections and salt caverns (DE: Germany, NL: Netherlands, BE: Belgium, LU: Luxemburg, FR: France, IT: Italy).

\subsubsection{Hydrogen storage}

Salt caverns and gaseous hydrogen vessels are used in the design in terms of hydrogen storage technologies. Although vessels can be installed in all regions, the availability of salt caverns depends on the existence of suitable salt structures. As indicated in Figure 2, the utilization of salt caverns is possible in Germany, the Netherlands and southern and eastern France. The maximum technical storage potential of salt caverns is determined by using the vector files of the appropriate salt structures within the regions. First of all, an eligibility analysis is performed on the salt structures to ensure that caverns are not built in inappropriate areas, as determined by a review of the literature [37-42]. An eligibility analysis is conducted using the Geospatial Land Availability for Energy Systems (GLAES) tool [43]. To ensure a salt cavern's above-ground facility is not too close to settlement areas, a $2500 \mathrm{~m}$ and $2000 \mathrm{~m}$ respective buffer distance from urban and rural areas are used as constraints [37]. Moreover, a buffer of $200 \mathrm{~m}$ for each of the major fault zones, natural protected areas, water bodies, railways, major roads and gas pipelines is 
used. To represent these geospatial features, the "Prior" datasets associated with the GALES tool are used [43], except for natural gas pipelines [35] and fault zones [44]. Finally, thin-bedded salt layers and salt domes are shrunk by $2000 \mathrm{~m}$ and $500 \mathrm{~m}$ from their edges to ensure cavern construction in stable pure-salt structures [45]. The placement of caverns with a volume of $500,000 \mathrm{~m}^{3}$ for thin-bedded salt structures and $750,000 \mathrm{~m}^{3}$ is performed for the eligible areas. These caverns are placed in such a way that the distance between the centers of two caverns is equal to four times the cavern diameter. This corresponds to nearly $340 \mathrm{~m}$ in the thin-bedded layers, and $230 \mathrm{~m}$ for salt-domes. The separation distance in the salt domes has a smaller value, as taller and thinner (smaller diameter) salt caverns can be built. In the case of thin-bedded salt layers, the cavern height is limited by the thickness of the salt structure. A $1400 \mathrm{~m}$ depth for placing the salt caverns in the salt domes is used, whereas the depth value is determined by the depth of the salt structure in the thin-bedded layers. Assuming a temperature of $15^{\circ} \mathrm{C}$ and gradient of $25^{\circ} \mathrm{C} / \mathrm{km}$, the average temperature in the middle of the cavern is estimated to calculate the cavern storage capacity [45].

\subsubsection{Hydrogen production}

In terms of conversion technologies, polymer electrolyte membrane electrolyzers (PEMELs) are employed in order to produce hydrogen from electricity generated via wind turbines due to their development in terms of performance, as well as the decrease in the investment cost [46]. An efficiency of $70 \%$ is assumed for a high pressure PEMEL with an investment cost of $500 € / \mathrm{kW}$ $[5,47]$.

\subsubsection{Electricity generation via wind turbines}

Onshore and offshore wind energy are viable electricity generation options. Simulation workflows and cost models for these technologies, previously published by Ryberg et al. [48] and Caglayan et al. [49], are employed in order to determine hourly electricity generation, as well as to estimate the investment cost of the turbines in each region. These workflows require an annual set of gridded climate model weather data, as well as the placement of the wind turbines and turbine design characteristics as inputs. The outputs of both workflows include the total hourly generation time series and maximum installable capacities of these technologies, which can be derived by summing the capacities of the individual placement of the wind turbines within each region. Finally, the hourly time series data are divided by the maximum capacities so that normalized generation data are obtained.

Wind speeds at $50 \mathrm{~m}$ are obtained by using the modern-era retrospective analysis for the research and applications (MERRA) dataset [50]. This dataset has a spatial resolution of $0.65^{\circ} \mathrm{x}$ $0.50^{\circ}$ covering the regions of interest and an hourly temporal resolution. It is available for the years starting from 1980, which enables an investigation of 37 years. Wind speeds at $50 \mathrm{~m}$ are projected to the hub height of wind turbines by drawing on roughness lengths suggested by Silva et al. [51] in response to location-specific land cover, as defined by the Corine land cover (CLC) dataset [52]. The power curves of wind turbines are used to determine power output corresponding to the wind speeds calculated at the hub heights. The convolution of the power curve similar to that employed 
by Staffel and Pfenninger [53] is applied, as well as generation-dependent loss factors. This algorithm for wind turbine simulations is employed for both onshore and offshore wind turbines.

Onshore wind energy: A set of typical exclusion criteria with buffer distances is applied to the regions using the GLAES model [43]. As suggested by Ryberg et al. [48], future-oriented onshore turbine designs are placed with a separation distance of eight times the rotor diameter in the wind speed direction and four times the rotor diameter in the transversal direction. Turbine characteristics at each location are also determined by the method employed by Ryberg et al. [48]. For each weather year, turbines placed within a region are simulated by using the aforementioned algorithm, which is described in detail by Ryberg et al. [48]. Following that, the normalized time series data of all turbines within a region is calculated and used as the onshore wind energy generation profile. Finally, the normalized data, average investment cost of onshore wind turbines per region and maximum capacities, as well as other economic parameters, are introduced to the optimization model as a generation technology representing onshore wind energy.

Offshore wind energy: Similar to land eligibility applied for onshore wind turbines, available areas for offshore turbines are determined using the same constraints, methodology and area definition explained by Caglayan et al. [49]. Following this, the distribution of optimal turbine designs across the eligible areas is performed with a separation distance of 10 times the rotor diameter in the wind speed direction and four times rotor diameter in the transversal direction. Rotor diameter values are estimated from the optimal turbine designs. All turbines are simulated by using the workflow for offshore wind energy in order to obtain the normalized time series data within each region and then defined as offshore wind energy generation in the model. In the end, the normalized time series, average cost of offshore wind turbines and maximum capacities per region are introduced to the optimization model as a generation technology representing offshore wind energy.

\section{EVALUATION OF AVERAGE FULL LOAD HOURS}

In this section, the input time series data representing onshore and offshore wind energy are evaluated by the average full load hours for each year and region. Hourly generation time series of onshore and offshore wind energy were estimated using the methodology briefly explained in Section 2.2.5 for each year. Future-oriented designs suggested by Ryberg et al. [48] for onshore and Caglayan et al. [49] for offshore wind turbines are used in the simulations. By using individual turbine placements within each region, an average generation profile is obtained and then used to estimate the full load hours.

\subsection{Average Full Load Hours of Wind Turbines}

Figure 3 shows the average full load hours of onshore and offshore wind turbines for each region and year. These values are calculated by simulating all possible turbine locations within a region, estimating the overall electricity generation from these, and finally dividing the total generation by the total installable capacity (summation of simulated turbine capacities). Average full load hours for onshore wind energy and offshore wind energy over all regions and years were 
found to be 2375 and $3970 \mathrm{~h} / \mathrm{a}$, respectively. For onshore wind energy, the Netherlands, northern France, southern France, western France, Belgium-Luxemburg, northwestern Germany, Sardinia and eastern France are above this average, with values of 3000, 2820, 2775, 2675, 2520, 2500, 2410 and $2500 \mathrm{~h} / \mathrm{a}$, respectively. Regions such as southern Italy, northeastern Germany, Corsica, Switzerland, middle Italy, northern Italy, southeastern and southwestern Germany have average onshore full load hours of 2290, 2285, 2270, 2120, 2020, 2000, 1980 and 1900, respectively. In terms of offshore wind energy, all of the regions except the Italian ones have higher full load hours, ranging between 4100 to5200 h/a. Sardinia and southern Italy have nearly $3200 \mathrm{~h} / \mathrm{a}$ average full load hours for offshore wind energy. For offshore wind energy, these values decrease to approximately $2100 \mathrm{~h} / \mathrm{a}$ for the middle and northern Italian regions.

Figure 3 shows two groups of regions according to the average full load hours for offshore wind energy. The first group, which can be considered as the regions with higher generation potential, includes northern Germany, the Netherlands, Belgium-Luxemburg and France. The average full load hours of the first group varies between 3500 and $5600 \mathrm{~h} / \mathrm{a}$. In the case of the second group involving Italian regions, the average full load hours are lower, with a range of 1600 to $3500 \mathrm{~h} / \mathrm{a}$. For example, northern Italy has average full load hours of $2400 \mathrm{~h} / \mathrm{a}$ when the weather year is chosen as 2003, which decreases to $2300 \mathrm{~h} / \mathrm{a}$ in 1993 and 2001. For northwestern Germany, the average full load hours are twofold of northern Italian values, ranging between 4700 and 5600 $\mathrm{h} / \mathrm{a}$. It must be noted that estimation of the average full load hours (derived from generation time series and maximum installable capacities) is performed without applying any means of filtering to the placement files. In other words, all possible turbine locations, both for onshore and offshore wind turbines, have been considered in this analysis. Both for onshore and offshore wind energy, the exclusion of turbine locations by a criterion such as average wind speed or minimum full load hours could enhance the overall generation within the region, as including low generation locations decreases the average generation. Therefore, the average generation and full load hours presented in this analysis can be increased if such a filtering method is applied; nevertheless, the definition of the criterion and threshold for filtering remains unclear. It may also cause a misinterpretation of the results. In addition to filtering the turbines, turbine placement as a result of the eligibility scenario can also affect the generation time series. The application of different constraints in the eligibility analysis might result in a different placement scheme; hence, different full load hours. Nevertheless, a uniformly applied eligibility scenario is employed, as an extensive analysis of this aspect does not fit within the scope of this analysis.

A detailed analysis of the average full load hours shows that claiming a single year with low or high wind generation (both onshore and offshore wind turbines) for all regions is questionable. For instance, wind power generation in most of the regions was relatively low in 1989 and 2016; however, northwestern Germany has a higher FLH compared to the average. Turning to the average full load hours in 1997, all of the regions exhibit lower generation except middle and southern Italian regions. Smaller regions can experience similar weather behavior in some years; nevertheless, wind turbine performance in all regions for a year cannot be classified as good or bad. 


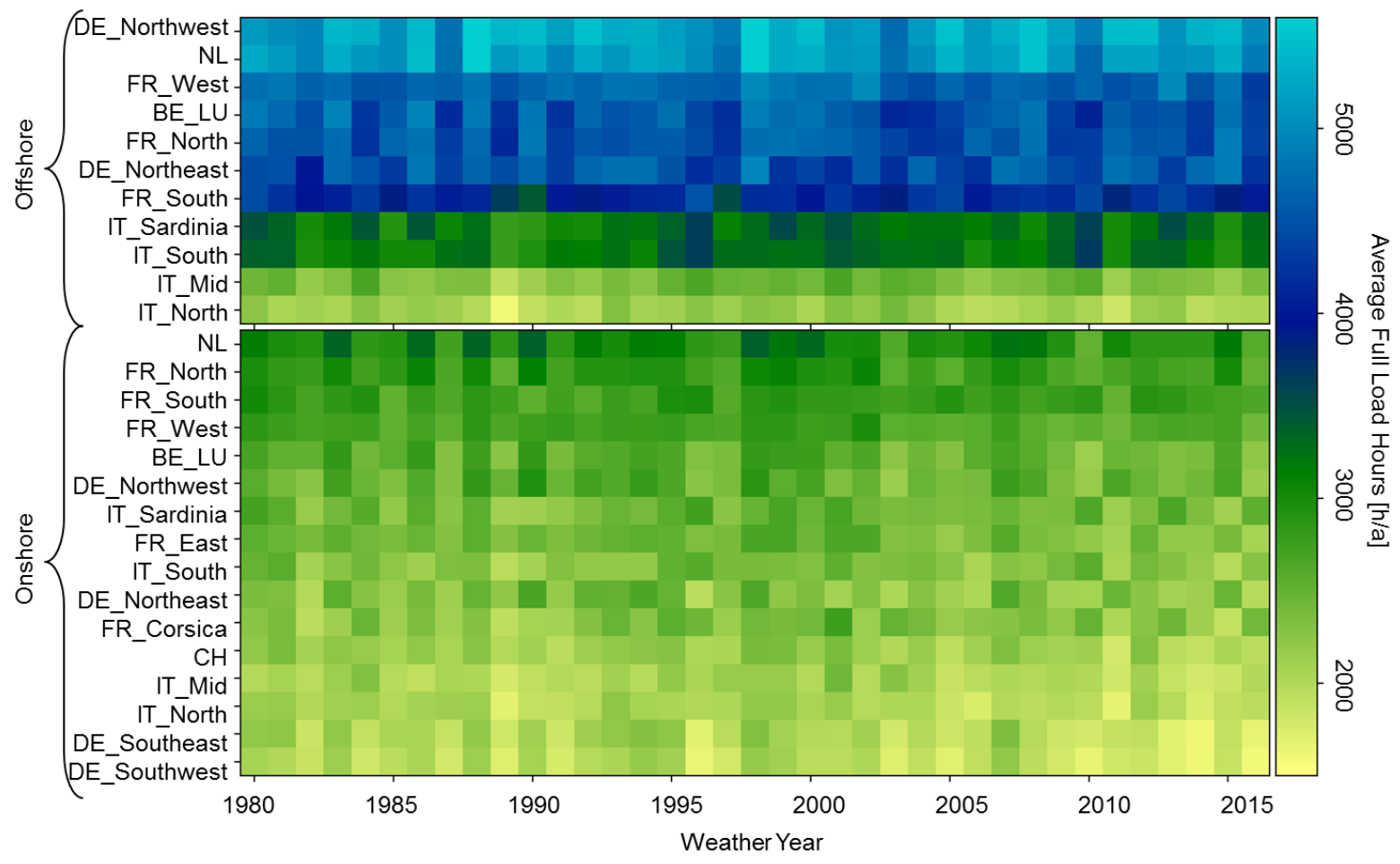

Figure 3. Average full load hours of onshore and offshore wind energy in the regions considered.

The change in the average full load hours presented in Figure 3 can be represented in terms of percent deviation from the regional average full load hours in order to better observe the dynamics. For this purpose, the percentage difference in the average full load hour of a region for a year can be calculated by using the overall average full load hours (for a region over all years) as a reference. Thus, the derivation of this deviance for each region, as well as the overall region of interest, is shown in Figure 4. Each gray line in the plot indicates the trends of the individual region, while the dashed blue line is for the variation of all regional context (variation of the average of all regions), while the pink line is added as an exemplary region in southern France. In some years, such as 1989, a strong negative deviation from the long-term average full load hour of some countries can be observed, while others like southern France in this instance show only small deviations. Another example with regionally heterogeneous deviations of average full load hours is the weather year 2011, in which many regions experience positive deviations in their average full load hours for both onshore and offshore wind energy. Moreover, that year can be considered as one of the worst weather years for southern France, as the average full load hour is the second lowest after the weather year 1985. However, the average full load hours in Germany in terms of onshore and offshore wind energy experience a positive deviation in the same year. As it is discussed earlier, the variation in the average full load hours of regions reveals that a summarily low or high wind generation year cannot be identified for all regions by looking at their average full load hour. 


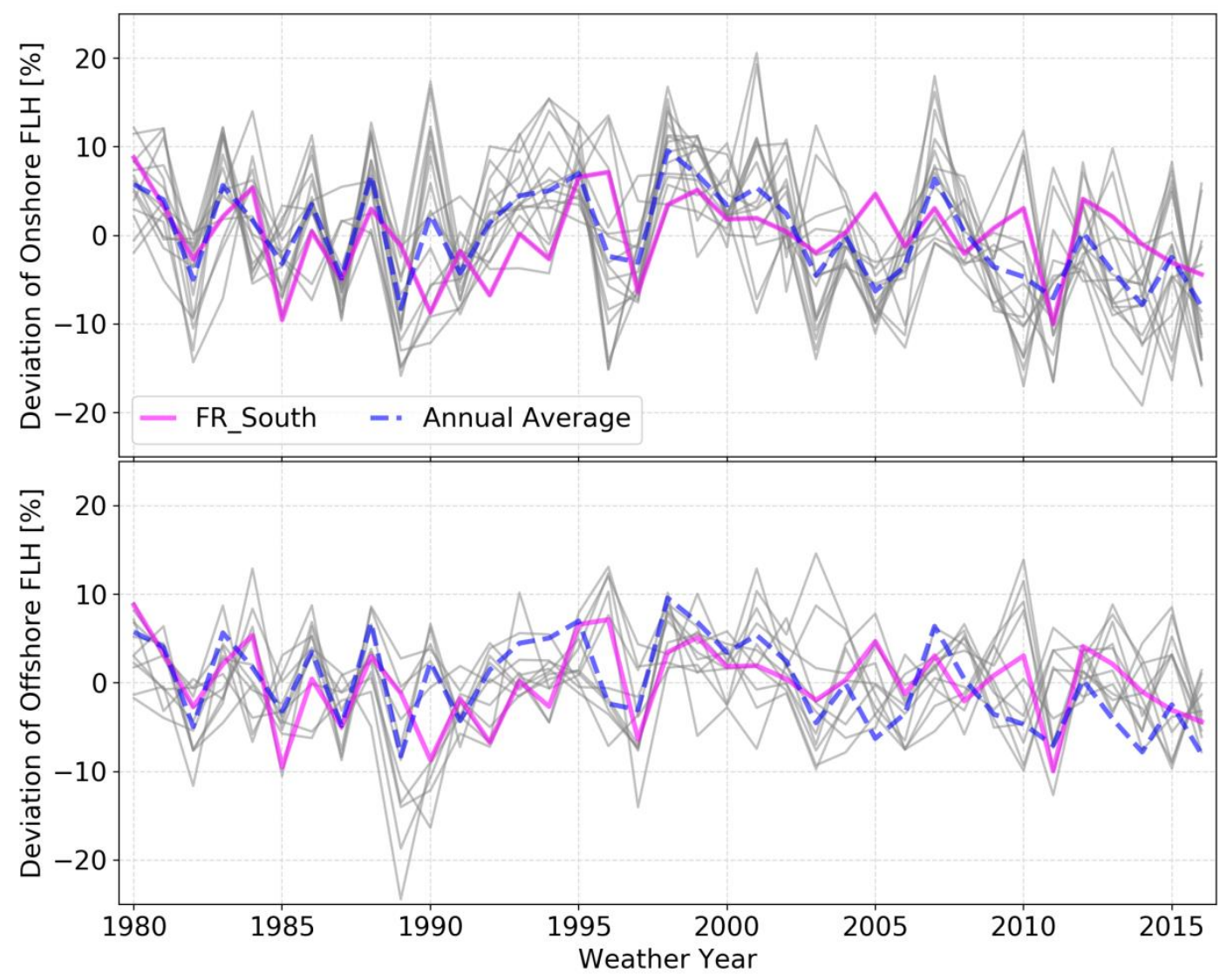

Figure 4. Percent deviation of onshore and offshore average full load hour with respect to the average full load hour of each region.

\section{RESULTS AND DISCUSSION}

In total, 37 model runs were performed using the methodology outlined in Section 2. These model runs differ by the generation time series of wind energy technologies available in the regions, as the time series data are obtained through the simulation of different weather years, ranging from 1980 to 2016. The average full load hours in each region for each year are examined in order to determine whether a low generation or high generation (good) weather year exists within these 37 years. Moreover, the relationship between average full load hours and system design is investigated and presented in the following sections.

\subsection{Electricity Generation}

The regional electricity generation via onshore and offshore wind turbines for each year, obtained as a result of the optimization, is shown in Figure 5. In 7 regions (Eastern France, Switzerland, Southern Germany and Italian regions, except Sardinia), there is no wind turbine installation. Belgium-Luxemburg, northern Germany, the Netherlands and southern France are the regions in which wind energy is generally utilized due to their high generation potential (high full load hours), unlike northern Italy, Switzerland, eastern France or southern Germany. These differences in wind energy generation potential result in more centralized production of hydrogen 
in regions with high wind energy generation potential supplying the hydrogen demand in all regions.

An analysis of regional contributions to electricity generation reveals that either onshore or offshore wind energy is utilized in Netherlands in most of the years. Similarly, onshore wind energy in southern France has a high share of electricity generation. Aside from these two regions, offshore wind energy utilization in Belgium-Luxemburg (an offshore area in Belgium) is observed in nearly $85 \%$ of the years owing to high full load hours and lower specific costs of turbines compared to the other regions (the latter is mainly due to the low shore distance, which plays a significant role in the offshore turbine cost). The installation of onshore wind turbines in northern France is found to be optimal in 1983, 1987 and 1990. Similarly, western France contributes to the electricity generation in $14 \%$ of the years by utilizing onshore wind turbines. When generation in northeastern and northwestern Germany is analyzed, offshore wind energy is utilized in northeastern Germany (Baltic Sea) in preference to northwestern Germany (North Sea), despite the relatively lower average full load hours observed in northeastern Germany. This is mainly because of the average specific cost of the turbines, which are significantly affected by the shore distance in northwestern Germany due to its maritime boundaries, extending over $400 \mathrm{~km}$ from the coast.

In addition to alterations in regional contributions to overall electricity generation, there is a notable variation in the distribution between onshore and offshore wind energy. In some years, a notable amount of electricity is generated with onshore wind turbines, especially in the Netherlands and southern France. However, electricity was mainly generated via offshore wind turbines in 2005 and 2016. In 1984 and 1995, the opposite behavior is observed, meaning that onshore wind energy is the dominant generation technology. Finally, although it is not as clear as in other regions, a switch between onshore and offshore wind energy in Sardinia can be observed through a closer look at the generations. All in all, regional distribution and different weather years reveal that the switch occurs not only between technologies, but also between regions. Although high generation potential regions are mostly utilized, differences in the optimal results in terms of regional preferences are apparent. 

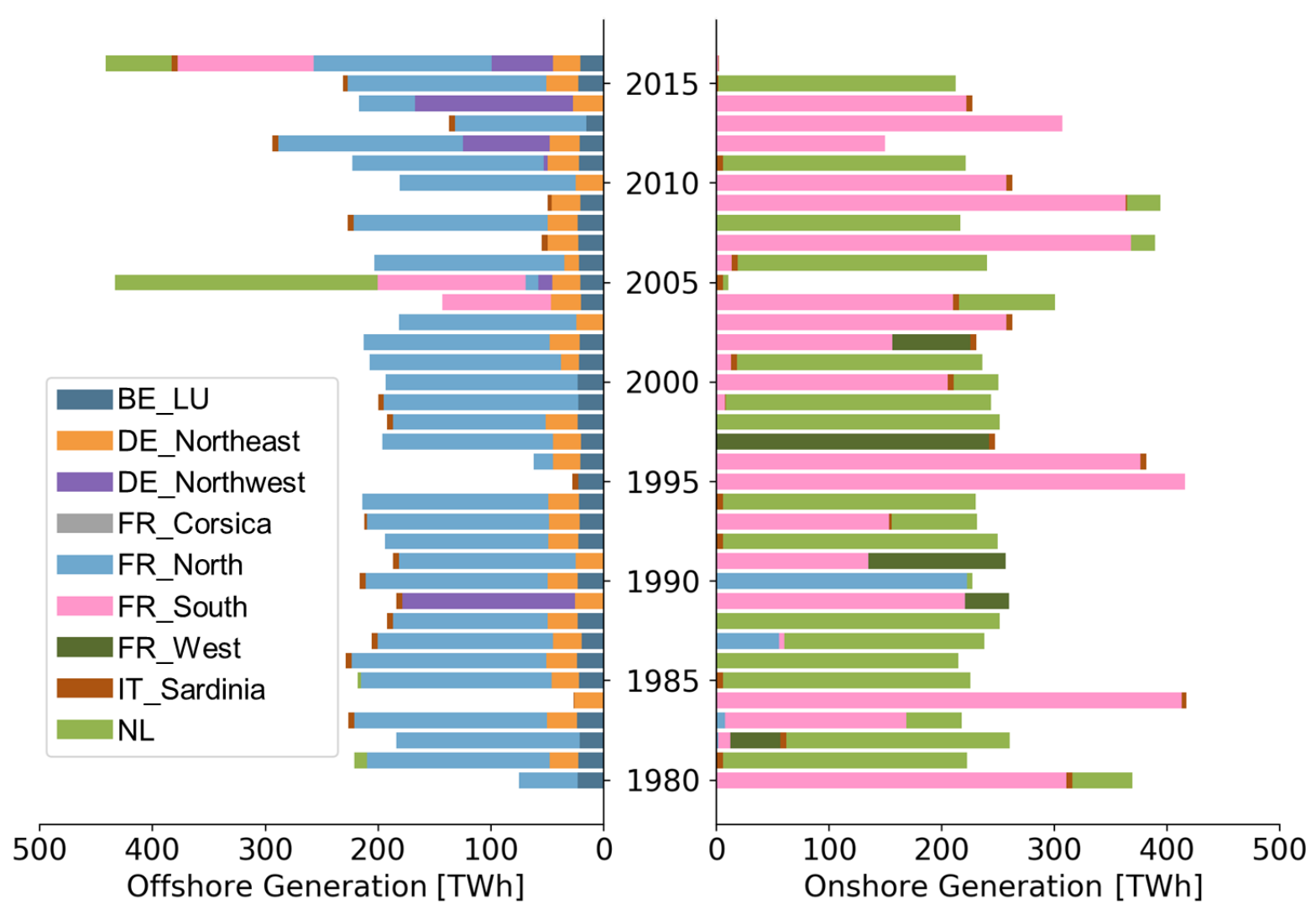

Figure 5. Distribution of onshore and offshore wind power generation in each region for different years.

\subsection{Hydrogen Pipeline Capacity}

Figure 6 illustrates the optimal pipeline capacities for hydrogen transport between regions, as well as electricity generation in each region as a result of the optimization for the years 1984, 1997, 1998 and 2014. These weather years are specifically chosen from amongst the 37 years investigated in this analysis due to the differences in the resulting system designs.

There are two important aspects to the weather year 1984. The highest onshore wind energy generation of the 37 years investigated in this analysis is observed in this year. Moreover, the high potential of southern France in that year makes this region the source that has the highest generation and hydrogen export potential to the neighboring regions. In addition, northeastern Germany produces hydrogen through offshore wind energy to supply the demand in that region, as well as its neighboring region (northwestern Germany). When pipeline connections are analyzed, the impact of salt cavern availability plays a significant role in the design of the pipeline network. Hence, large pipeline capacities between southern France and Switzerland, as well as Switzerland and southwestern Germany, are seen due to the high storage potential of these regions (southern France and southwestern Germany). Therefore, it can be stated that the hydrogen produced is transported to southwestern Germany and stored there to be used in the time periods when the hydrogen produced is not sufficient to supply the regional demand. 
The reason why the results of the weather years 1997 and 1998 are chosen is to visualize the difference in the designs of the two consecutive years. Variation in the designs of these years are especially in France, as the regions where most wind turbines are installed differ between these years. Aside from northeastern Germany and Belgium-Luxemburg generating electricity in both years, northern and western France are the regions where the most electricity was generated in the weather year 1997, whereas it was northern France and the Netherlands in 1998. In addition to the alterations in the regions generating electricity, the pipeline design varies significantly in the northern regions. It can be seen that western France supplied hydrogen to the Italian regions and Switzerland in 1997. Nevertheless, the demand in these regions was supplied by the Netherlands over southwestern Germany in 1998.

The fourth exemplary system design is given for the weather year 2014, as it shows different wind energy generation and pipeline connections compared to the other three years. When this year is analyzed, it can be seen that pipeline connections between the regions and their capacities are similar to the weather year of 1984. However, the regions where hydrogen is produced differ. Instead of importing hydrogen from southern France, eastern France is connected to northern France, thus importing it from there. Moreover, northwestern Germany becomes a main producer for the northern regions.

To summarize, considerable variations in the system designs can be seen both in regions where electricity is generated and connections between regions. Depending on the locations where wind turbines are installed, pipeline connections between regions vary. Moreover, the regions where salt caverns are available are used for the storage of hydrogen. Hydrogen supply to Switzerland and the Italian regions in particular occurs from either southwestern Germany or southern France due to their salt cavern availability. 


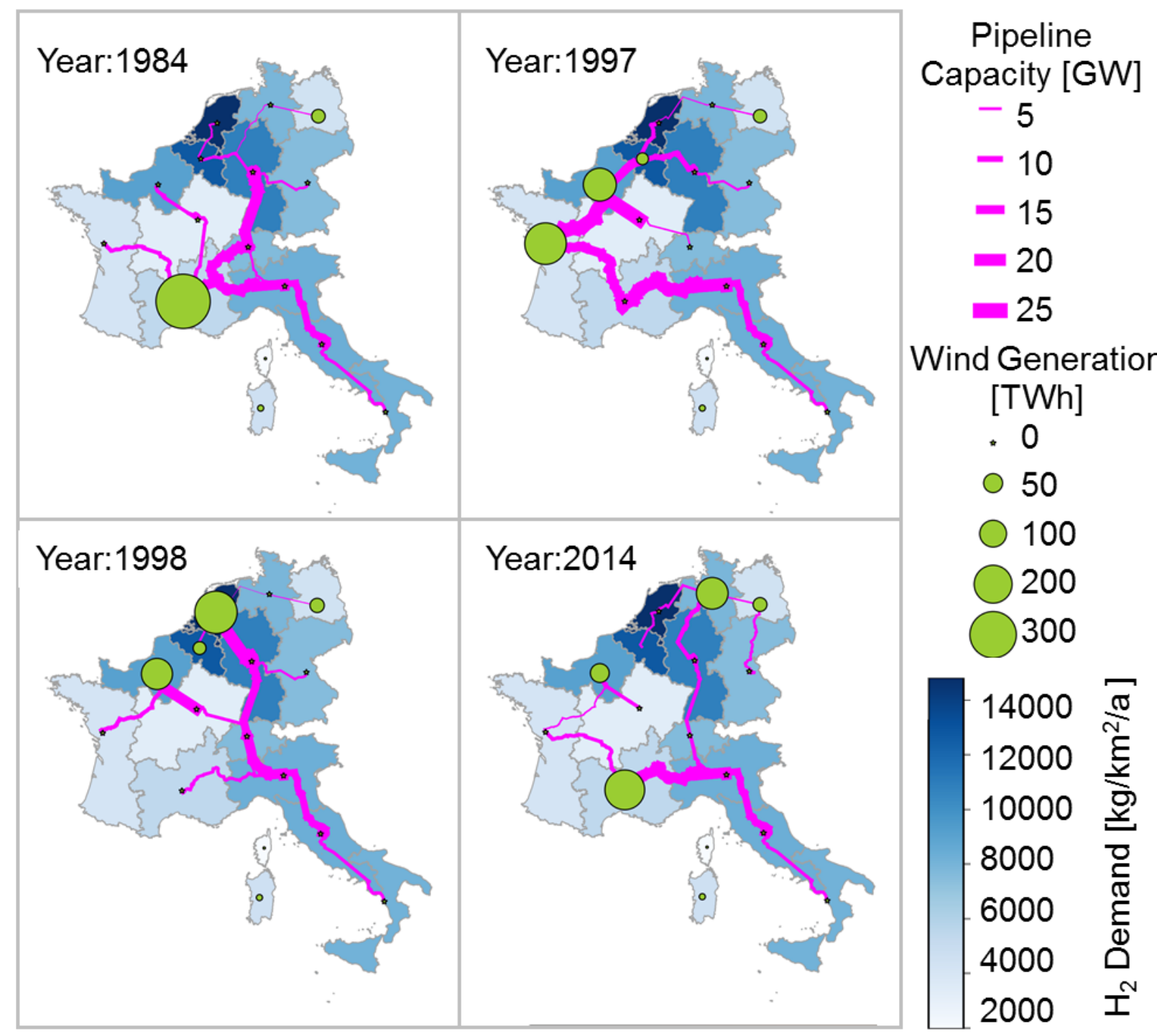

Figure 6. Optimization results including pipeline capacity and wind power generation to supply the assumed hydrogen demand for the transport sector for the selected weather years.

\subsection{Hydrogen Pipeline Counting}

Pipeline connections and the capacities of the pipes between regions as a result of the optimization differ with respect to weather years (cf. Section 4.2). The number of repetitions of the pipeline connections between regions across all weather years is presented in Figure 7. All pipeline connections utilized in each weather year are converted into binary variables independently of their capacity. These binaries are summed up across all weather years in order to observe how many years each connection are chosen. For example, the red line labeled with 2837 represents those pipeline connections that are repeated in almost all of the years (with a maximum of 37 years). 
It is noticed that there are some connections being built in only one to four cases amongst the 37 weather years; for instance, the connection between eastern France and southwestern Germany, as well as Belgium-Luxemburg. In contrast, it is also evident that some pipeline connections are repeatedly built. In particular, pipeline connections between Italian regions are most frequently built due to the fact that Italian regions are not preferred for wind turbine installation because of their lower potential for wind power (see Figure 3). As it is more economical to transport hydrogen from regions with higher wind energy potential, there must be pipeline connections between all regions, where it is not possible to store hydrogen in salt caverns (hydrogen storage in vessels is not chosen because it would be more expensive) and the utilization of wind energy is not chosen by the optimizer. Because of this, hydrogen demand in Switzerland and Italy is met by transporting hydrogen from high wind power generation regions for all weather years. However, this figure might change when photovoltaic (PV) generation is also considered as an additional technology owing to the high potential in the Italian regions. Currently, PV technologies are not considered due to the lack of tools for creating generation time series. Nevertheless, the overall system design, involving many technologies, should be taken into account in future analyses.

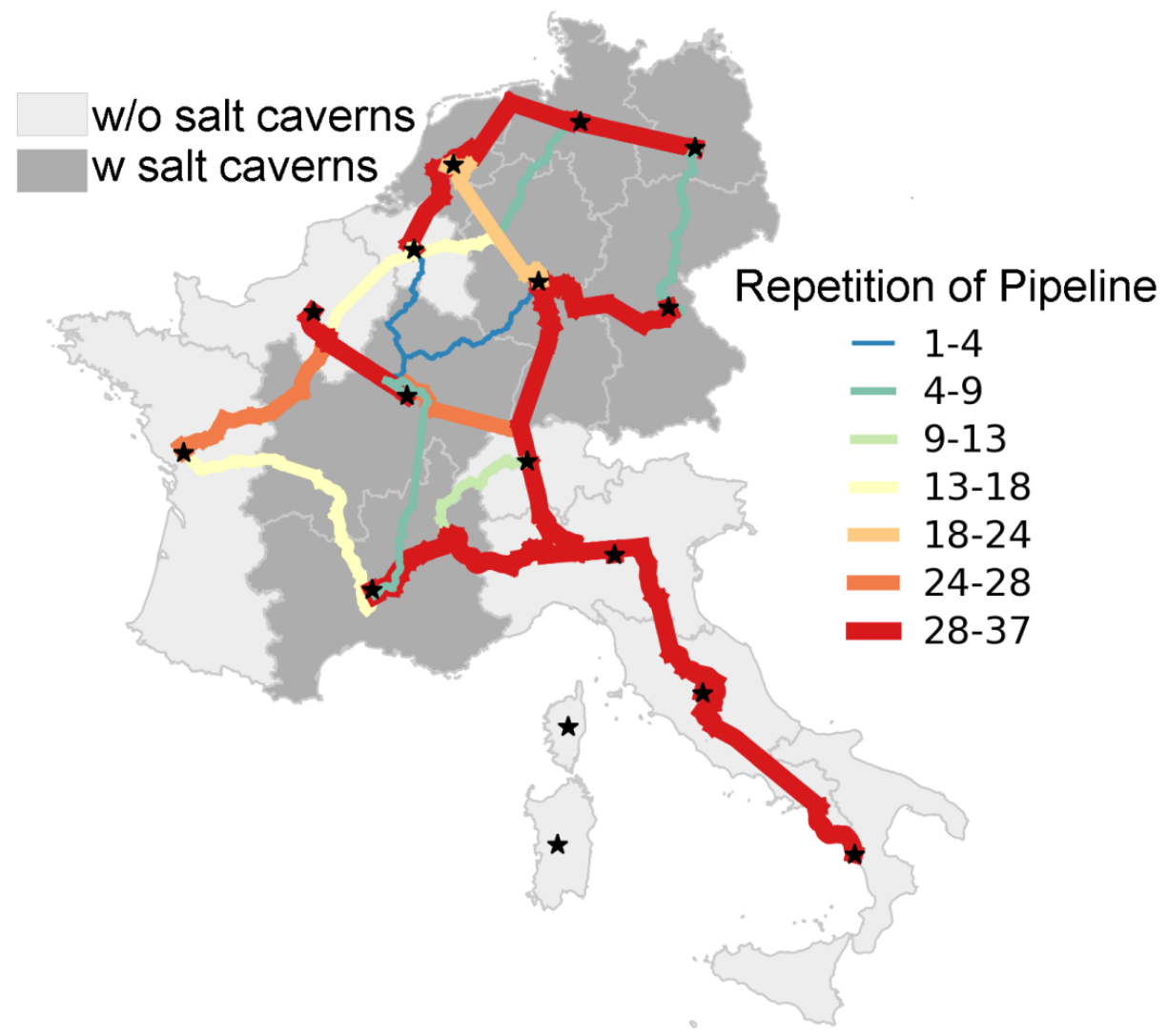

Figure 7. Repetition of hydrogen pipeline routing as a result of the optimization of each weather year in regions with and without the potential for salt caverns. 


\subsection{Total Annual Cost}

The change in the share of components in the total annual cost (TAC) as a result of the optimization with respect to each weather year can be seen in Figure 8. The scale is normalized by the resulting TAC of the weather year 1980, which has a value of 34.3 Billion $€ /$ a. It is seen that the normalized TAC of the system varies between $96 \%$ and $115 \%$ of the 1980 s' value. These values correspond in total to 32.9 Billion $€ /$ a and 39.7 Billion $€ / a$, respectively. However, the most significant change in the TAC is observed in the two consecutive weather years, 1997 and 1998, with an approximate difference of 16 Billion $€ /$ a. Significant variation in the TAC is caused by the weather year chosen, as the total installed wind turbine capacity increases with lower power generation to supply the exogenously-fixed demand, which is constant for all years.

A major portion of the TAC comes from wind turbine and electrolyzer costs in all weather years, while the contributions of technologies such as pipelines, salt caverns and vessels are relatively small. The shares between onshore and offshore wind turbines can also be observed in Figure 8. It can be seen that there are almost no onshore wind turbines installed in the weather year 2016, while a significant portion of the hydrogen demand is supplied by onshore wind turbines in the weather years 1995 or 1984 . The change in the installed capacities of onshore and offshore wind energy generation is caused by differences in the average full load hours in each weather year. As the underlying optimization minimizes the overall TAC, even slight changes in cost result in a technology shift; in this case from onshore to offshore or vice versa. In relatively cheaper systems, such as for the weather years 1980, 1983, 1988 and 1998, the installed capacities of onshore and offshore wind turbines are similar in each weather year with the comparable TAC of systems. A deeper look at the most expensive years reveals that different shares of offshore and onshore wind energy can be seen, especially in the weather years of 1989, 2003 and 2016. Therefore, it can be stated that neither higher onshore nor offshore installed capacities cause higher TAC. Weather years in which higher TAC is observed correspond to lower FLH in the high potential wind energy regions. For instance, weather years such as 1989 and 1997 are those in which high wind potential regions like the Netherlands, as well as some regions in France and northern Germany, have relatively lower average onshore and offshore FLH.

In addition to the shares of onshore and offshore wind turbine costs, total capacity, FLH and the cost of electrolyzers alternate in each weather year due to variation in the installed capacity of wind turbines. The installed capacities of electrolyzers are determined within the optimization. They depend on the installed capacities of wind turbines, as well as the fluctuations in wind power generation, as there is curtailed wind energy due to the cost optimality within the optimization. Therefore, the share of electrolyzers in the TAC varies between 7.9 Billion $€ /$ a and 9.9 Billion $€ / a$. 


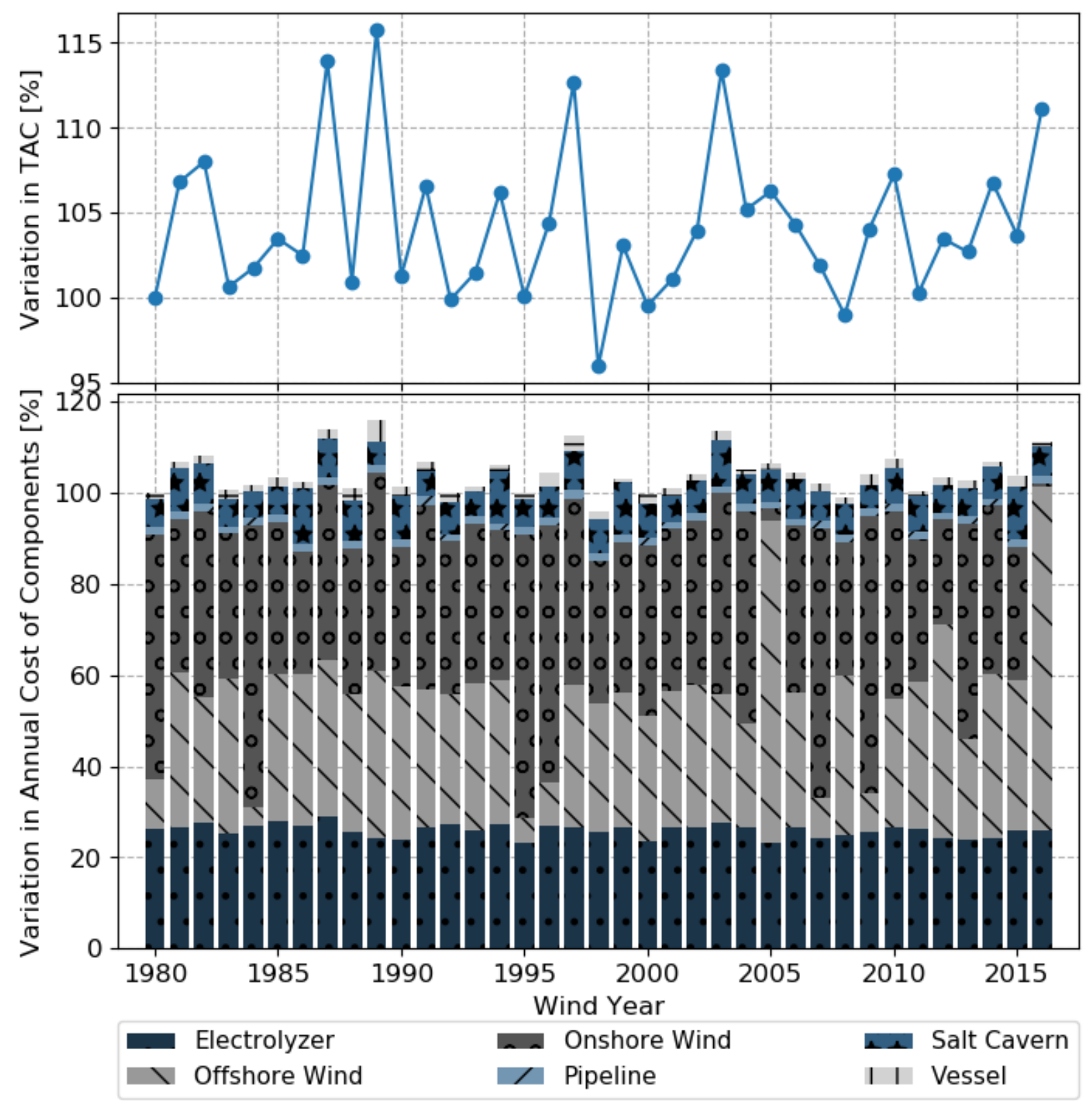

Figure 8. Normalized total annual cost of system with respect to weather years.

\section{CONCLUSIONS}

The influence of historical weather years between 1980 and 2016 in an exemplary, multinational wind-based energy system to supply hydrogen demand for passenger vehicles is investigated. In order to obtain the system design for each historical weather year, an optimization framework (FINE), which has an objective function of minimization of the total annual cost (TAC) of the system, was independently utilized for each year. The cost-optimal results are compared by means of average full load hours (FLH), installed capacities of onshore and offshore wind turbines and the costs of the components in the system. The average FLH of wind power generation reveals 
that there is no precise weather year in which all regions have low or high power generation. Identification of the worst or best weather year in terms of power generation for an international context is fairly challenging, as it depends on the location. These variations in the average FLH results in different system designs in terms of the installed capacities of onshore and offshore wind turbines, the regions in which wind turbines are installed and hydrogen pipeline connections, as the behavior of each region alters in each weather year. For instance, the FLH of most of the regions are relatively lower in the weather year 1989, whereas southern France has higher FLH than its own average amongst the weather years investigated. Concerning the previous comments on the variations between weather years, it can be said that the time slice chosen for such an analysis is crucial. For example, there is only a slight variation between 1994 and 1995, yet when the time slice is chosen between 1997 and 1998, the difference becomes apparent.

Hydrogen pipeline connections and their capacities between regions are sensitive to the selected weather year. Although some regions are occasionally connected, perpetual pipeline connections are distinguished amongst the connected Italian regions. It is ascertained that transporting hydrogen via pipeline from higher wind potential regions to the lower potential regions is cost-optimal in all weather years. Regions with relatively lower FLH, such as Switzerland, eastern France and Italy are either connected to high potential regions or to regions that can store hydrogen in salt caverns. However, some infrequent pipeline connections exist between regions having similar wind energy potential. All in all, although there is a perpetual pipeline connection and some variations, the share of pipeline connections in TAC is less than 5\%, meaning that this technology is not an obstacle to the design.

Fluctuation in optimal system design is evident between the weather years. This is seen in both the TAC and in the ratio between the installed capacities of onshore and offshore wind turbines. By looking at these variations, it can be concluded that using one weather year to design an energy system is not robust. As a result, it can be said that in order to have robust results that capture future energy system behavior, multiple weather years should be considered. Another approach could be to design the system in an iterative manner. If perpetual design parameters are kept constant and other parts of the system are re-optimized, a robust solution could be achieved. However, such an iterative approach cannot fully guarantee finding the cost-optimal solution amongst the robust design options. The spatial clustering of wind regions can be an alternative to having a robust system design. The utilization of high wind potential clusters may decrease the variations in the installed capacities of wind turbines within the regions, and also prevent the switch between regions.

In addition, the impact of some extensions of the exemplary energy system on variations due to weather years can be included in further studies. For example, solar energy can be considered alongside wind energy to observe the variation of the weather year on the system design. Whether wind and solar energy generation compensate each other by changing weather year, or if consideration of both increases the variations in the system designs, are the questions to be answered. Another option could be to consider the electrical grid as a further option to transfer 
energy between regions and include further energy demand, such as electricity for the transport sector.

\section{ACKNOWLEDGMENTS}

This work was supported by the Helmholtz Association under the Joint Initiative, "EnergySystem 2050 - A Contribution of the Helmholtz Research Field Energy".

\section{REFERENCES}

[1] Olivier JGJ, Peters JAH. Trends in global CO2 and total greenhouse gas emissions: 2018 Report. The Hague: 2018.

[2] International Renewable Energy Agency. Capacity and Generation n.d. http://resourceirena.irena.org/gateway/dashboard/ (accessed January 22, 2018).

[3] Albadi MH, El-Saadany EF. Overview of wind power intermittency impacts on power systems. Electr Power Syst Res 2010;80:627-32.

[4] Robinius M, Otto A, Heuser P, Welder L, Syranidis K, Ryberg D, et al. Linking the Power and Transport Sectors_Part 1: The Principle of Sector Coupling. Energies 2017;10:956. doi:10.3390/en10070956.

[5] Schiebahn S, Grube T, Robinius M, Tietze V, Kumar B, Stolten D. Power to gas: Technological overview, systems analysis and economic assessment for a case study in Germany. Int J Hydrogen Energy 2015;40:4285-94. doi:10.1016/j.ijhydene.2015.01.123.

[6] Samsatli S, Staffell I, Samsatli NJ. Optimal design and operation of integrated windhydrogen-electricity networks for decarbonising the domestic transport sector in Great Britain. Int J Hydrogen Energy 2016;41:447-75. doi:10.1016/j.ijhydene.2015.10.032.

[7] Le Duigou A, Quéméré M-M, Marion P, Menanteau P, Decarre S, Sinegre L, et al. Hydrogen pathways in France: Results of the HyFrance3 Project. Energy Policy 2013;62:1562-9. doi:10.1016/j.enpol.2013.06.094.

[8] Robinius M, Otto A, Syranidis K, Ryberg DS, Heuser P, Welder L, et al. Linking the Power and Transport Sectors-Part 2: Modelling a Sector Coupling Scenario for Germany. Energies 2017;10:957. doi:10.3390/en10070957.

[9] Welder L, Ryberg DS, Kotzur L, Grube T, Robinius M, Stolten D. Spatio-temporal optimization of a future energy system for power-to-hydrogen applications in Germany. Energy 2018;158:1130-49. doi:10.1016/j.energy.2018.05.059.

[10] EnergyPlan. EnergyPLAN - Advanced energy systems analysis computer model. 2019.

[11] Heide D, Greiner M, von Bremen L, Hoffmann C. Reduced storage and balancing needs in a fully renewable European power system with excess wind and solar power generation. Renew Energy 2011;36:2515-23. doi:10.1016/j.renene.2011.02.009.

[12] Heide D, von Bremen L, Greiner M, Hoffmann C, Speckmann M, Bofinger S. Seasonal optimal mix of wind and solar power in a future, highly renewable Europe. Renew Energy 2010;35:2483-9. doi:10.1016/j.renene.2010.03.012.

[13] Rodríguez RA, Becker S, Andresen GB, Heide D, Greiner M. Transmission needs across a fully renewable European power system. Renew Energy 2014;63:467-76. 
doi:10.1016/j.renene.2013.10.005.

[14] Schlott M, Kies A, Brown T, Schramm S, Greiner M. The impact of climate change on a cost-optimal highly renewable European electricity network. Appl Energy 2018;230:164559. doi:10.1016/j.apenergy.2018.09.084.

[15] Bogdanov D, Breyer C. North-East Asian Super Grid for 100\% renewable energy supply: Optimal mix of energy technologies for electricity, gas and heat supply options. Energy Convers Manag 2016;112:176-90. doi:10.1016/j.enconman.2016.01.019.

[16] Gulagi A, Bogdanov D, Breyer C. The role of storage technologies in energy transition pathways towards achieving a fully sustainable energy system for India. J Energy Storage 2018;17:525-39. doi:10.1016/j.est.2017.11.012.

[17] Elliston B, MacGill I, Diesendorf M. Least cost 100\% renewable electricity scenarios in the Australian National Electricity Market. Energy Policy 2013;59:270-82. doi:10.1016/j.enpol.2013.03.038.

[18] Budischak C, Sewell D, Thomson H, Mach L, Veron DE, Kempton W. Cost-minimized combinations of wind power, solar power and electrochemical storage, powering the grid up to $99.9 \%$ of the time. J Power Sources 2013;225:60-74. doi:10.1016/j.jpowsour.2012.09.054.

[19] Fripp M. Switch: A Planning Tool for Power Systems with Large Shares of Intermittent Renewable Energy. Environ Sci Technol 2012;46:6371-8. doi:10.1021/es204645c.

[20] Ashok S. Optimised model for community-based hybrid energy system. Renew Energy 2007;32:1155-64. doi:10.1016/j.renene.2006.04.008.

[21] Jung J, Villaran M. Optimal planning and design of hybrid renewable energy systems for microgrids. Renew Sustain Energy Rev 2017;75:180-91. doi:10.1016/j.rser.2016.10.061.

[22] Nfah EM, Ngundam JM, Tchinda R. Modelling of solar/diesel/battery hybrid power systems for far-north Cameroon. Renew Energy 2007;32:832-44. doi:10.1016/j.renene.2006.03.010.

[23] Lund H, Mathiesen BV. Energy system analysis of 100\% renewable energy systems-The case of Denmark in years 2030 and 2050. Energy 2009;34:524-31. doi:10.1016/j.energy.2008.04.003.

[24] Haller M, Ludig S, Bauer N. Decarbonization scenarios for the EU and MENA power system: Considering spatial distribution and short term dynamics of renewable generation. Energy Policy 2012;47:282-90. doi:10.1016/j.enpol.2012.04.069.

[25] Dagdougui H, Ouammi A, Sacile R. Modelling and control of hydrogen and energy flows in a network of green hydrogen refuelling stations powered by mixed renewable energy systems. Int J Hydrogen Energy 2012;37:5360-71. doi:10.1016/j.ijhydene.2011.07.096.

[26] Pfluger B, Wietschel M. Impact of renewable energies on conventional power generation technologies and infrastructures from a long-term least-cost perspective. 2012 9th Int. Conf. Eur. Energy Mark., IEEE; 2012, p. 1-10. doi:10.1109/EEM.2012.6254768.

[27] Pfenninger S. Dealing with multiple decades of hourly wind and PV time series in energy models: A comparison of methods to reduce time resolution and the planning implications 
of inter-annual $\quad$ variability. Appl $\quad$ Energy $2017 ; 197: 1-13$. doi:10.1016/j.apenergy.2017.03.051.

[28] European Environmental Agency. Europe's Onshore and Offshore Wind Energy Potential: An Assessment of Environmental and Economic Constraints. Copenhagen: 2009. doi:10.2800/11373.

[29] Bauelos-Ruedas F, Angeles-Camacho C, Sebastin. Methodologies Used in the Extrapolation of Wind Speed Data at Different Heights and Its Impact in the Wind Energy Resource Assessment in a Region. In: Suvire GO, editor. Wind Farm - Tech. Regul. Potential Estim. Siting Assess., InTech; 2011. doi:10.5772/20669.

[30] Welder L, Heinrichs H, Linßen J, Robinius M, Stolten D. Framework for Integrated Energy Systems Assessment (FINE) 2018. https://github.com/FZJ-IEK3-VSA/FINE.

[31] Kotzur L, Markewitz P, Robinius M, Stolten D. Impact of different time series aggregation methods on optimal energy system design. Renew Energy 2018;117:474-87. doi:10.1016/j.renene.2017.10.017.

[32] Kotzur L, Markewitz P, Robinius M, Stolten D. Time series aggregation for energy system design: Modeling seasonal storage. Appl Energy 2018;213:123-35. doi:10.1016/j.apenergy.2018.01.023.

[33] Reuß M, Grube T, Robinius M, Preuster P, Wasserscheid P, Stolten D. Seasonal storage and alternative carriers: A flexible hydrogen supply chain model. Appl Energy 2017;200:290-302. doi:10.1016/j.apenergy.2017.05.050.

[34] European Commission, Joint Research Centre, University C, Network C for IESI. GHS population grid, derived from GPW4, multitemporal (1975, 1990, 2000, 2015) 2015.

[35] WorldMap. Natural Gas Pipelines in Europe, Asia, Africa \& Middle East n.d. https://worldmap.harvard.edu/data/geonode:natural_gas_pipelines_j96 (accessed April 4, 2017).

[36] Earth N. 1:10 m Cultural Vectors n.d. http://www.naturalearthdata.com/downloads/10mcultural-vectors/ (accessed April 4, 2017).

[37] Andreas Acht. Salzkavernen zur Wasserstoffspeicherung. RWTH Aachen University, 2013.

[38] Hou MZ, Xie H, Yoon JS, editors. Underground storage of CO2 and energy. Proc. SinoGerman Conf., Beijing: CRC Press Taylor \& Francis; 2010.

[39] Wang T, Yang C, Ma H, Daemen JJK, Wu H. Safety evaluation of gas storage caverns located close to a tectonic fault. J Nat Gas Sci Eng 2015;23:281-93. doi:10.1016/j.jngse.2015.02.005.

[40] Parkes D, Evans DJ, Williamson P, Williams JDO. Estimating available salt volume for potential CAES development: A case study using the Northwich Halite of the Cheshire Basin. J Energy Storage 2018;18:50-61. doi:10.1016/j.est.2018.04.019.

[41] Stolzenburg K. Wietschel M., Geneose F., Michaelis J., Lehmann J., Miege A., Krause S., Donadei S., Crotogino F., Acht A., Horvath P-L. HR, Stolzenburg K. Wietschel M., Geneose F., Michaelis J., Lehmann J., Miege A., Krause S., Donadei S., Crotogino F., Acht A., Horvath P-L. HR, Stolzenburg K. Wietschel M., Geneose F., Michaelis J., Lehmann J., 
Miege A., Krause S., Donadei S., Crotogino F., Acht A., Horvath P-L. HR. Integration von Wind-Wasserstoff-Systemen in das Energiesystem: Abschlussbericht. Berlin: 2014.

[42] Fichtner. Erstellung eines Entwicklungskonzeptes Energiespeicher in Niedersachsen. 2014.

[43] Ryberg DS, Tulemat Z, Robinius M, Stolten D. Geospatial Land Availability for Energy Systems (GLAES) 2017.

[44] European database of active faults and seismogenic SHARE n.d. http://www.shareeu.org/node/70 (accessed October 10, 2018).

[45] Weber N. Assessment of the Technical and Economic Potential of Salt Deposits for Hydrogen Storage. RWTH Aachen University, 2018.

[46] Saba SM, Müller M, Robinius M, Stolten D. The investment costs of electrolysis - A comparison of cost studies from the past 30 years. Int J Hydrogen Energy 2018;43:120923. doi:10.1016/j.ijhydene.2017.11.115.

[47] Baufumé S, Grüger F, Grube T, Krieg D, Linssen J, Weber M, et al. GIS-based scenario calculations for a nationwide German hydrogen pipeline infrastructure. Int J Hydrogen Energy 2013;38:3813-29. doi:10.1016/j.ijhydene.2012.12.147.

[48] Ryberg DS, Caglayan DG, Schmitt S, Linßen J, Stolten D, Robinius M. The Future of European Onshore Wind Energy Potential: Detailed Distribution and Simulation of Advanced Turbine Designs. Preprints 2018. doi:10.20944/preprints201812.0196.v1.

[49] Caglayan DG, Ryberg DS, Heinrichs H, Linßen J, Stolten D, Robinius M. The technoeconomic potential of offshore wind energy with optimized future turbine designs in Europe. 2019.

[50] Rienecker MM, Suarez MJ, Gelaro R, Todling R, Bacmeister J, Liu E, et al. MERRA: NASA's Modern-Era Retrospective Analysis for Research and Applications. J Clim 2011;24:3624-48. doi:10.1175/JCLI-D-11-00015.1.

[51] Silva J, Ribeiro C, Guedes R. Rougness Length Classification of Corine Land Cover Classes 2000:1-10. http://citeseerx.ist.psu.edu/viewdoc/download;jsessionid=5553BF237EA27088446BF89B 39E2CA6E?doi=10.1.1.608.2707\&rep=rep1\&type=pdf (accessed May 14, 2017).

[52] Copernicus Land Monitoring Service. Corine Land Cover (Version 18.5.1) 2012.

[53] Staffell I, Pfenninger S. Using bias-corrected reanalysis to simulate current and future wind power output. Energy 2016;114:1224-39. doi:10.1016/j.energy.2016.08.068. 